九州大学学術情報リポジトリ

Kyushu University Institutional Repository

\title{
Encapsulation of Industrial Cationic Pollutants from Aqueous Solution by Nanocrystalline Cellulose and It' s Modified Forms
}

Roy, Hridoy

Department of Chemical Engineering, Bangladesh University of Engineering and Technology

M. Motiur Rahman

Department of Chemistry, Bangladesh University of Engineering and Technology

Yeasin A. Tarek

Department of Chemistry, Bangladesh University of Engineering and Technology

Shakhawat H. Firoz

Department of Chemistry, Bangladesh University of Engineering and Technology

https://doi.org/10.5109/4738576

出版情報: Proceedings of International Exchange and Innovation Conference on Engineering \& Sciences (IEICES). 7, pp.116-121，2021-10-21. 九州大学大学院総合理工学府

バージョン:

権利関係 : 


\title{
Encapsulation of Industrial Cationic Pollutants from Aqueous Solution by Nanocrystalline Cellulose and It's Modified Forms
}

\author{
Hridoy Roy ${ }^{1}$, M. Motiur Rahman², Yeasin A. Tarek ${ }^{2}$, Shakhawat H. Firoz ${ }^{2 *}$ \\ ${ }^{1}$ Department of Chemical Engineering, Bangladesh University of Engineering and Technology, Dhaka-1000, Bangladesh \\ ${ }^{2}$ Department of Chemistry, Bangladesh University of Engineering and Technology, Dhaka-1000, Bangladesh \\ *Corresponding author email: shfiroz@chem.buet.ac.bd
}

\begin{abstract}
Adsorbents based on nanocrystalline cellulose (NCC) were synthesized by two steps selective functionalization at C-2, C-3 position of glucose moiety/structure resulting in an intermediate product, di-aldehyde nanocrystalline cellulose (DANC) and final product, di-carboxylate nanocrystalline cellulose (DCNC). The success offunctionalization reaction was confirmed by FTIR and SEM. The removal of basic blue 41 was then investigated by varying process parameters such as initial solution $\mathrm{pH}$, contact time and initial dye concentration. The adsorption kinetics were investigated using pseudo $1^{\text {st }}$ and pseudo $2^{\text {nd }}$-order model; which fitted well to the later one. Meanwhile, adsorption isotherm study predicted monolayer adsorption mechanism following the Langmuir model with a calculated maximum adsorption capacity of $446.19 \mathrm{mg} / \mathrm{L}$ for DCNC, which was much higher compared to DANC and NCC. The reusability studies configured that DCNC can be reused at least 5 cycles without losing significant efficiency. These findings prefigure that DCNC is an excellent biodegradable adsorbent.
\end{abstract}

Keywords: Nanocrystalline cellulose (NCC); Selective functionalization; Dicarboxylate nanocrystalline cellulose (DCNC); Cationic dyes; Biodegradability.

\section{INTRODUCTION}

Synthetic dyes in large variety and quantity are used by textile-based industries. Moreover, food, pharmaceutical and paper industries use dye in the production process. As a consequence, huge amounts of the dyes added in the process remain unconsumed and ultimately find their way to water bodies. So, removal of dyes from industrial effluent to a non-hazardous level before releasing into the natural water bodies is a challenge for industries. In recent years, various physicochemical and biological strategies, such as coagulation/flocculation, membrane separation, ion exchange and many others have been developed for removing dyes from wastewater. In terms of economic feasibility and sustainability adsorption is considered as one of the viable methods due to its simple and low cost design process and high efficiency[1]. Thus, in the past few decades development of adsorbents with high activity for removal of organic pollutants has gained great significance [2]. In this perspective, cellulose and its modified forms are considered to be the most effective candidates to introduce versatile group of adsorbents [3]. Cellulose is the one of the most abundant linear polysaccharides that contain repeating unit of $\beta-1$, 4-D-glucose and three hydroxyl groups per a hydro glucose unit. The -OH rich structure of cellulose provides a excellent platform to introduce a large number active adsorption sites and functionality in the structure to favor the adsorption process [4]. Microcrystalline cellulose (MCC) consists of amorphous and crystalline regions, when subjected to hydrolysis, MCC results in nanocrystalline cellulose (NCCs). Compared to MCC, NCC has higher aspect ratio, larger surface area, and larger number of reactive surface groups [5]. In addition, low toxicity, biodegradability and ecological sustainability of NCC has introduced intriguing application prospects and makes it well suited for the fabrication of functional adsorbent [6]. To the date, several adsorbent materials based on NCCs have already been reported for the efficient adsorption of toxic pollutants. Despite an extended use of cellulose and derivatives of cellulose as adsorbents, there is still considerable continuing research into the use of different forms of cellulose as adsorbents. The aim of this work is to ascertain the potentiality of dicarboxylate nanocellulose (DCNC) adsorbent as a versatile adsorbent in the removal of an industrial toxic dye, basic blue 41 (BB41). Sodium Periodate and sodium chlorite was utilized as an oxidizing agent for introducing multiple carboxylic groups onto NCCs via ring-opening oxidation reaction. The adsorption behavior of BB41 onto NCC, DANC and DCNCs, including the factors potentially affecting the adsorption process were investigated. Finally, the recyclability of DCNCs for the dye adsorption were also examined.

\section{MATERIALS}

Microcrystalline cellulose (MCC), sodium metaperiodate $\left(\mathrm{NaIO}_{4}\right)$, ethylene Glycerol $\left(\mathrm{C}_{2} \mathrm{H}_{6} \mathrm{O}_{2}\right)$, hydrogen peroxide $\left(\mathrm{H}_{2} \mathrm{O}_{2}\right)$, ethanol $\left(\mathrm{C}_{2} \mathrm{H}_{5} \mathrm{OH}\right)$, sodium chloride $(\mathrm{NaCl})$, sodium chlorite $\left(\mathrm{NaClO}_{2}\right)$, sodium hydroxide $(\mathrm{NaOH})$, basic blue 41(BB41), methylene blue (MB), basic blue 3(BB3) were bought from sigma Aldrich and Merck, Germany. Deionized (DI) water was used to make the solutions.

\section{METHODS}

3.1 Preparation of the adsorbents

The DCNC was prepared by the two-step selective oxidation, according to a method described earlier[7]. Briefly, $100 \mathrm{~mL}$ of $63.5 \%$ (w/w) $\mathrm{H}_{2} \mathrm{SO}_{4}$ was poured in a $500 \mathrm{~mL}$ round bottom flask and MCC was mixed with the solution. Then, the mixture was continuously stirred for $90 \mathrm{~min}$ at $60^{\circ} \mathrm{C}$ to prepare $\mathrm{NCC}$. The selective functionalization process of NCC was performed to obtain dialdehyde nanocrystalline cellulose (DANC). In this process, $13.38 \mathrm{~g}$ of solid $\mathrm{NaIO}_{4}$ was added to $2 \%$ (w/v) NCC suspension of volume $500 \mathrm{~mL}$ and continuously stirred in the absence of light at $48^{\circ} \mathrm{C}$ in an oil bath for 20 hours (aluminum foil was used to cover the reaction flask). Relatively excess amount of ethylene glycol was mixed to terminate the reaction and a suspension of DANC was formed. Then, DANC was converted into DCNC by a mild oxidation reaction. All the $-\mathrm{CHO}$ groups of DANC were expected to be convert into - $\mathrm{COOH}$ groups at this stage. [8] In this process, 2:1 ratio of $\mathrm{NaCl}(4.0 \mathrm{~g})$ and $\mathrm{NaClO}_{2}(2.0 \mathrm{~g})$ was maintained and $5.0 \mathrm{~mL}$ of $\mathrm{H}_{2} \mathrm{O}_{2}$ were mixed to $150 \mathrm{~mL}(0.001223$ 
$\mathrm{g} / \mathrm{L})$ suspension of DANC. The reaction mixture was then continuously stirred $(400 \mathrm{rpm})$ for 24 hours at room temperature (around $27^{\circ} \mathrm{C}$ ). To stop the reaction, an excess amount of ethanol was slowly poured into the reaction media which resulted in a gelatinous precipitate of DCNC (yellowish). Finally, the formed precipitate was thoroughly washed with DI water and stored in the refrigerator (in suspension form) at about $4-10^{\circ} \mathrm{C}$ for experimental studies and characterization. To obtain the solid particle the suspension was then freeze dried.

\subsection{Characterizations of adsorbents}

Morphological analysis of NCC, DANC and DCNC were executed by using JSM-7600F Field Emission Scanning Electron Microscopy (FESEM/SEM). SHIMADZU FTIR-8400 spectrometer was used to collect the Fourier Transform Infra-red (FT-IR) spectra. The range of the FT-IR spectra was $400-4000 \mathrm{~cm}^{-1}$ and 45 scans were taken for each sample at a resolution of $4 \mathrm{~cm}^{-1}$ with $\mathrm{KBr}$ pellets sampling.

\subsection{Adsorption and reusability studies}

The adsorption behaviors of NCC, DANC and DCNCs were systematically investigated towards BB41 by varying the parameters including initial solution $\mathrm{pH}$, contact time and initial dye concentration. In each experiment, the amount of NCC, DANC and DCNCs was $10 \mathrm{mg}$. The $\mathrm{pH}$ effect on adsorption process was examined by changing the solution $\mathrm{pH}$ from 2.0 (very acidic) to 10.0 (very basic). To adjust the $\mathrm{pH}$ value, 0.1 $\mathrm{M} \mathrm{NaOH}$ and $\mathrm{HCl}$ solution was used. Kinetic studies were conducted with an initial dye concentration of 150 ppm at room temperature and each sample were analyzed at time intervals ranging from 10 to $250 \mathrm{~min}$. Initial concentration dependence and isotherm studies were conducted with various initial dye concentrations $\left(\mathrm{C}_{\mathrm{o}}=\right.$ 20-350 $\mathrm{mg} / \mathrm{L}$ ) for $200 \mathrm{~min}$.

The removal (\%) [9] and the adsorption capacity at equilibrium $\left(\mathrm{q}_{\mathrm{e}}, \mathrm{mg} / \mathrm{g}\right)$ of the dye were calculated according to the Eqs (1) and (2), respectively:

Removal, $\%=\frac{\left(C_{i}-C_{e}\right) \times 100}{C_{i}}$

$q=\frac{\left(C_{i}-C_{e}\right) \times V}{m}$

To determine the reusability, BB41 loaded DCNC was centrifuged at 3,000 rpm and dried in an air oven. Then, $50 \mathrm{~mL}$ of $70(\mathrm{w} / \mathrm{v}) \%$ ethanol solution was added and the mixture was shaken at room temperature for $400 \mathrm{~min}$. Then, the DCNC was utilized for subsequent sorption cycles. The adsorption/desorption cycles were continued for 5 consecutive cycles to establish the viability and feasibility of repeated use of the bio-sorbent. The adsorption efficiency of each cycle was estimated as a percentage of the uptake of the first adsorption by the following equation.

Sorption Efficiency, $\%=\frac{\text { qith cycle } \times 100}{\mathrm{q} \text { initial }}$

Here, $\mathrm{q}_{\text {ith }}(\mathrm{mg} / \mathrm{g})$ is the adsorption capacity at ith cycle and $\mathrm{q}_{\text {initial }}(\mathrm{mg} / \mathrm{g})$ is the adsorption capacity at first cycle.

\section{RESULTS AND DISCUSSIONS}

The synthesis of desired adsorbent DCNC) was started from micro crystalline cellulose (MCC). Micro crystalline cellulose was firstly converted to nano crystalline cellulose (NCC) by ultrasound assisted acid hydrolysis. Periodate oxidation was used to introduce the aldehyde group to the 2 and 3 positions by cleaving the C2-C3 bond of NCC. It was used due to its highly specific reactivity to be converted into 1, 2-dihydroxyl groups (glycol) to paired aldehyde groups without any significant side reactions. Due to its sensitivity to light, the reaction was done in absence of light. The aldehyde group was then further oxidized to prepare $\mathrm{Na}$-salt of dicarboxylate nanocrystalline cellulose. Previous works paved the way to use sodium chlorite in this step [8].

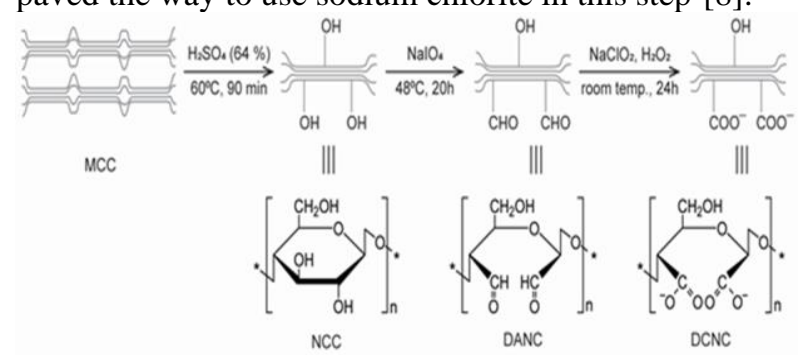

Fig. 1. Schematic representation of the synthesis process of DCNC from MCC via NCC and DANC

The FTIR spectra of the NCC and its functionalized forms are presented in Fig. 2. It provided strong evidence of successful preparation of NCC from MCC and further oxidation of NCC to DANC and DCNC. For NCC, the wide peak at $3400 \mathrm{~cm}^{-1}$ is assigned to the $\mathrm{O}-\mathrm{H}$ stretching bands and the peak at $2903 \mathrm{~cm}^{-1}$ corresponds to the saturated aliphatic symmetric $\mathrm{C}-\mathrm{H}$ stretching vibrations of cellulose[10].

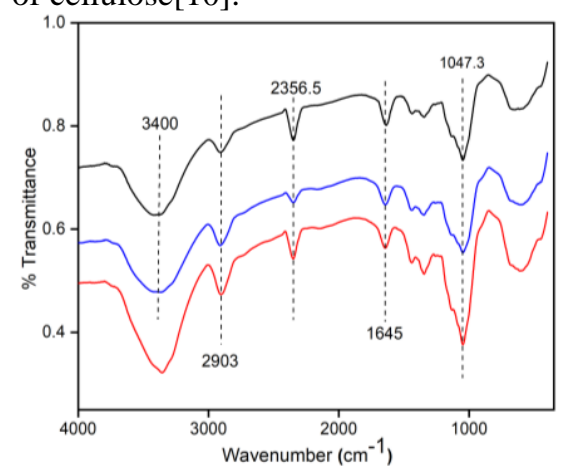

Fig. 2. FTIR spectra of NCC (black), DANC (blue) and DCNC (green)

The peaks detected at $1645 \mathrm{~cm}^{-1}$ and $1375 \mathrm{~cm}^{-1}$ are attributed to the $\mathrm{O}-\mathrm{H}$ bending modes of absorbed water and $\mathrm{C}-\mathrm{H}$ bending within the polysaccharide rings of cellulose respectively[11]. Peaks at $1047.30 \mathrm{~cm}^{-1}$ imputed to pyranose ring stretching vibration of $\mathrm{C}-\mathrm{O}-\mathrm{C}$ and $898 \mathrm{~cm}^{-1}$ was due to $\beta$-glycosidic linkages of cellulose[12]. Fig. 2 illustrated similar FTIR patterns for DANC and DCNC showed that the basic chemical skeleton of nanocellulose were not changed after the further oxidation process, where the typical structure of the parent raw cellulose was being conserved [13].The functionality of the chlorite-oxidized DCNC was confirmed by the diminishing of the intensity of hemiacetal signal at $898 \mathrm{~cm}^{-1}$ and the appearance of band at $1450 \mathrm{~cm}^{-1}$ (very weak) in FTIR spectra of the DCNC due to dissociated form of carboxyl group . 


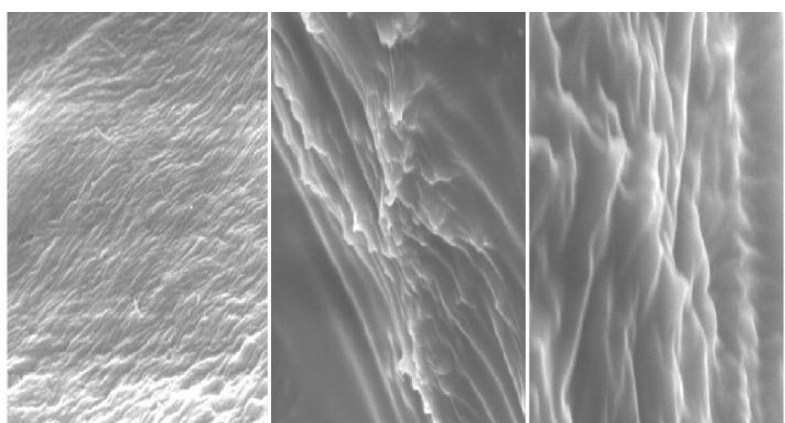

Fig. 3. FESEM images of NCC (left), DANC (middle) and DCNC (right)

SEM images were taken to describe morphologies of NCC and functionalized NCC, as shown in Fig. 3 and changes introduced in the surface morphologies due to the selective functionalization of NCC were observed from these images. The FESEM micrograph of a very dilute suspension of NCC, showed compact agglomerated cellulose nanocrystals[14]. The surface of NCC appeared to be smooth and contained very small amount of crack. The compact binding of NCCs suggested that cellulosic chains had intermolecular hydrogen bonding with a strong hydrophilic interaction in between the cellulosic chains. After periodate oxidation the surface of DANC expressed a small amount of fractured and convex impressions[15].During chlorite oxidation the dispersibility of DCNC increased compared to that of the NCC and DANC .The surface of DCNC was extremely rough and contained great number of microcracks. This was probably caused by the carboxyl contents introduced during the oxidation, which consequently increased the electrostatic repulsion between the cellulose chains. The starting dialdehyde cellulose seemed to be slightly agglomerated before chemical modifications but after chemical modification the gap between the chains increased and were found to be separated from each other [16]. Incorporation of relatively hydrophobic groups on the surface may results in the separation [17]. So, it can be concluded as the surface modifications occurred at every step of the oxidation process and microcracks in DCNC surface probably increased the surface area which promoted the adsorption capacity of this adsorbent.

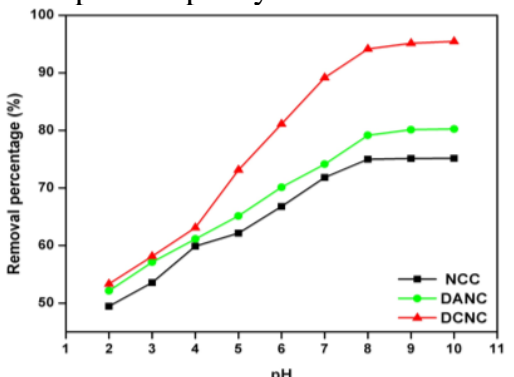

Fig. 4. Effect of pH on adsorption of BB41 by NCC (black), DANC (green) and DCNCs(red)

The initial $\mathrm{pH}$ of the dye solution is an important factor that controls the adsorption process by affecting the surface charge of the adsorbents and the ionization process of the dye molecules [18]. The removal rate of BB41 by DCNC, DANC and NCCs at different $\mathrm{pH}$ ranging from 2-10 is shown in Fig. 4.

In the $\mathrm{pH}$ range of $4.0-7.5$, the removal rate increases rapidly and the highest dye removal was attained around

at $\mathrm{pH} 8.0$, indicates the columbic electrostatic attraction between the cationic portion of dye molecules and the highly negatively charged sites/active sites on surface of adsorbents (COO-) is the crucial driving force and controlling factor for the adsorption process. At lower/acidic $\mathrm{pH}$, the competitive sorption between proton $\left(\mathrm{H}^{+}\right)$and dye reduces the affinity for the dye molecules to be attached onto the surface of the adsorbent; hence resulting poor adsorption capacity at lower $\mathrm{pH}$. With the increasing $\mathrm{pH}$, deprotonation process greatly escalate the electrostatic interaction between the positively charged portion dye molecules and the negatively charged sites of adsorbents surface resulting in a proportional and remarking increase of the adsorption[19]. When $\mathrm{pH}$ increases from 8.0 to 10.0 , the adsorption capacity does not change due to saturation of adsorption sites. This represents that DCNC can perform effectively over a basic range of $\mathrm{pH}$ compared with NCC and DANC, which might be ascribed to the high surface area and carboxylic groups introduced by oxidation in DCNC matrix. High number of -COO- groups provide reactive sites, which is favorable for cationic dyes removal.

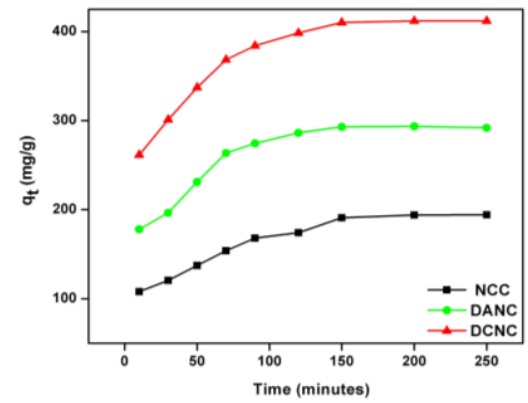

Fig. 5. Effect of time on adsorption of BB41 by NCC (black), DANC (green) and DCNCs(red)

The adsorption of BB41 by NCC, DANC and DCNCs were explored in the ranges of 10-250 min. As shown in Fig. 5. for all the adsorbents, sorption capacity increases expeditiously within first $100 \mathrm{~min}$ and then the increment gradient decreases as time passes. The adsorption reaches equilibrium at about $200 \mathrm{~min}$ for each adsorbent. The high removal efficiency at the initial period can be attributed to the fact that availability of vacant adsorption/active sites initially. After a certain lapse of time, the remaining vacant active sites are difficult to be occupied by the dye species, resulting in the decrease of adsorption rate as time passes

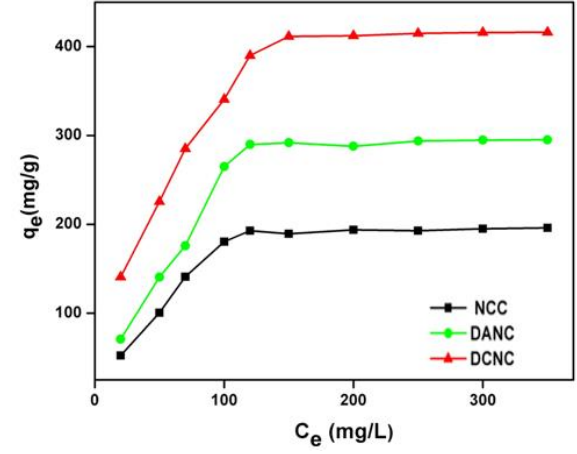


Fig. 6. Effect of initial concentration on adsorption of BB41 by NCC (black), DANC (green) and $\operatorname{DCNCs}($ red)

The results for the adsorption of BB41 onto NCC, DANC and DCNCs at different concentrations are shown in Fig. 6. With the initial dye concentration increment from 20 to $350 \mathrm{mg} / \mathrm{L}$, the equilibrium adsorption capacity of BB41 gradually increases from 42.567 to $196.1467 \mathrm{mg} / \mathrm{g}$ for NCCs, 59.925 to $295.125 \mathrm{mg} / \mathrm{g}$ for DANCs, and 108.809 to $416.07 \mathrm{mg} / \mathrm{g}$ for DCNCs. This behavior may be explained by the fact that the enhancement of the driving force between adsorbents and dye molecules with the increase of initial concentration [20]. In addition, the experimental adsorption capacity of DCNC at equilibrium is found to be much higher than that of DANC and NCCs, which further implies that the incorporated $-\mathrm{COOH}$ groups on DCNC improve the adsorption capacity greatly.
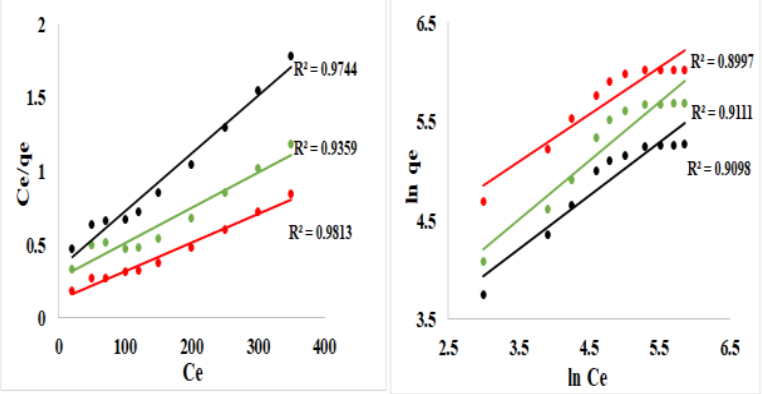

Fig. 7. Linear fittings of Langmuir (left) and Freundlich (right) isotherm of NCC (black), DANC (green) and DCNCs(red)

Isotherm analysis was performed to describe the dye removal process by NCCs, DANC and DCNC. The experimental adsorption data were explicated using two most common isotherm models, Langmuir and Freundlich model and adsorption behavior was explained and plotted as shown in Fig.7. Langmuir isotherm presumes a monolayer adsorption and consider that the adsorption sites are energetically homogenous and identical. Whereas, multilayer adsorption on heterogeneous surfaces of adsorbent was the main consideration of the Freundlich isotherm. In eqn. (4) and (5), linear expressions for both of the models are expressed respectively,

$\frac{\mathrm{C}_{\mathrm{e}}}{\mathrm{q}_{\mathrm{e}}}=\frac{1}{\mathrm{~b}_{\mathrm{L}} \mathrm{q}_{\mathrm{m}}}+\frac{\mathrm{C}_{\mathrm{e}}}{\mathrm{q}_{\mathrm{m}}}$

$\ln \mathrm{q}_{\mathrm{e}}=\frac{1}{\mathrm{n}} \ln \mathrm{C}_{\mathrm{e}}+\ln \mathrm{k}_{\mathrm{f}}$

Here, $\mathrm{C}_{\mathrm{e}}\left(\mathrm{mgL}^{-1}\right)$ is the equilibrium dye concentration after adsorption, $\mathrm{k}_{\mathrm{L}}$ defines the Langmuir adsorption constant, $\mathrm{k}_{\mathrm{F}}$ is the Freundlich adsorption constant, heterogeneity factor is $\mathrm{n}$. Where, $\mathrm{q}_{\mathrm{e}}$ and $\mathrm{q}_{\mathrm{m}}\left(\mathrm{mgg}^{-1}\right)$ represent the equilibrium and maximum adsorption capacity of dye on the adsorbent, respectively. The fitting results are summarized in Table1.

From the isotherm parameters values, it can be said that Langmuir isotherm model fits accurately to the adsorption data indicating that the adsorption process by NCC, DANC and DCNC are limited with monolayer coverage. In addition, the calculated adsorption capacity values are well in alignment with the experimental values which confirm applicability and feasibility of Langmuir model to explain the adsorption behavior of BB41 on the different forms of cellulose.

Table 1. Isotherm constants of Langmuir and Freundlich models for BB41 adsorption onto NCC, DANC and DCNCs

\begin{tabular}{cccccccc}
\hline & \multicolumn{3}{c}{ Langmuir } & \multicolumn{4}{c}{ Freundlich } \\
\cline { 2 - 7 } $\begin{array}{l}\text { Adsorbent } \\
s\end{array}$ & $\begin{array}{c}\mathrm{q}_{\mathrm{m}} \\
(\mathrm{mg} / \mathrm{g})\end{array}$ & $\begin{array}{c}\mathrm{b}_{\mathrm{L}} \\
(\mathrm{L} /\end{array}$ & $\mathrm{R}^{2}$ & $\begin{array}{c}\mathrm{k}_{\mathrm{f}} \\
(\mathrm{L} /\end{array}$ & $\mathrm{n}$ & $\mathrm{R}^{2}$ \\
& & $\mathrm{mg})$ & & $\mathrm{g})$ & & \\
\cline { 3 - 7 } DCNC & 446.2 & 0.030 & 0.98 & 88. & 4.10 & 0.89 \\
& & & & 9 & & \\
nANC & 314.8 & 0.029 & 0.93 & 56. & 3.17 & 0.91 \\
& & & & 9 & & \\
NCC & 212.3 & 0.023 & 0.97 & 47. & 2.83 & 0.90 \\
& & & & 1 & & \\
\hline
\end{tabular}

To study the interaction between adsorbate and adsorbent different models have been proposed. Two most commonly used models in terms of wide acceptability were pseudo $1^{\text {st }}$ order model and pseudo $2^{\text {nd }}$ kinetic

\begin{tabular}{|c|c|c|c|c|c|c|c|}
\hline & \multirow[b]{2}{*}{$\begin{array}{c}\mathrm{q}_{\mathrm{e}, \exp } \\
(\mathrm{mg} / \mathrm{g} \\
\quad)\end{array}$} & \multicolumn{3}{|c|}{$\begin{array}{l}\text { Pseudo } 1^{\text {st }} \\
\text { order }\end{array}$} & \multicolumn{3}{|c|}{$\begin{array}{l}\text { Pseudo } 2^{\text {nd }} \\
\text { order }\end{array}$} \\
\hline $\begin{array}{c}\text { Adsorb } \\
\text { ents }\end{array}$ & & $\begin{array}{c}\mathrm{K}_{1} \\
\left(\begin{array}{c}\min \\
-1\end{array}\right)\end{array}$ & $\begin{array}{c}\mathrm{q}_{\mathrm{e}, \mathrm{ca}} \\
1 \\
(\mathrm{mg} \\
/ \mathrm{g})\end{array}$ & $\mathrm{R}^{2}$ & $\begin{array}{c}\mathrm{K}_{2} \\
(\mathrm{~g} / \mathrm{m} \\
\mathrm{g} . \mathrm{mi} \\
\mathrm{n})\end{array}$ & $\begin{array}{c}\mathrm{q}_{\mathrm{e}, \mathrm{cal}} \\
(\mathrm{mg} / \\
\mathrm{g})\end{array}$ & $\mathrm{R}^{2}$ \\
\hline$N C C$ & $\begin{array}{c}193 . \\
9\end{array}$ & $\begin{array}{c}0.02 \\
2\end{array}$ & $\begin{array}{c}149 \\
.3\end{array}$ & $\begin{array}{l}0 . \\
87\end{array}$ & $\begin{array}{c}2.22 \\
\times 10^{-} \\
4\end{array}$ & $\begin{array}{l}212 \\
.76\end{array}$ & $\begin{array}{l}0.9 \\
91\end{array}$ \\
\hline$D A N C$ & $\begin{array}{c}293 . \\
5\end{array}$ & $\begin{array}{c}0.03 \\
5\end{array}$ & $\begin{array}{c}293 \\
.1\end{array}$ & $\begin{array}{c}0 . \\
91 \\
5\end{array}$ & $\begin{array}{c}2.34 \\
\times 10^{-} \\
4\end{array}$ & $\begin{array}{c}312 \\
.5\end{array}$ & $\begin{array}{l}0.9 \\
97\end{array}$ \\
\hline$D C N C$ & $\begin{array}{c}411 . \\
8\end{array}$ & $\begin{array}{c}0.03 \\
0\end{array}$ & $\begin{array}{c}298 \\
.2\end{array}$ & $\begin{array}{c}0 . \\
92 \\
5\end{array}$ & $\begin{array}{c}2 \times 10 \\
-4\end{array}$ & $\begin{array}{c}434 \\
.78\end{array}$ & $\begin{array}{l}0.9 \\
98\end{array}$ \\
\hline
\end{tabular}

model [21]. These two models have been used to understand the kinetics of adsorption process by NCC, DANC and DCNC.

Table 2. Kinetic parameters of Langmuir and Freundlich models for BB41 adsorption onto NCC, DANC and DCNCs

Pseudo $1^{\text {st }}$ order model consider the adsorption is controlled by the diffusion process, where adsorption is 
based on chemisorption for pseudo $2^{\text {nd }}$ order model. The integral pseudo first order equation can be illustrated as, $\ln \left(\mathrm{q}_{\mathrm{e}}-\mathrm{q}_{\mathrm{t}}\right)=\ln \mathrm{q}_{\mathrm{e}}-\mathrm{k}_{1} \mathrm{t}$

where, $\mathrm{q}_{\mathrm{e}}(\mathrm{mg} / \mathrm{g})$ and $\mathrm{q}_{\mathrm{t}}(\mathrm{mg} / \mathrm{g})$ indicates the adsorption capacity at equilibrium and at time $\mathrm{t}(\mathrm{min})$ respectively. Whereas, $\mathrm{k}_{1}\left(\mathrm{~min}^{-1}\right)$ represents the pseudo $1^{\text {st }}$ order rate constant.

The pseudo second order equation can be expressed as,

$\frac{\mathrm{t}}{\mathrm{q}_{\mathrm{t}}}=\frac{1}{\mathrm{k}_{2} \mathrm{qe}^{2}}+\frac{\mathrm{t}}{\mathrm{q}_{\mathrm{e}}}$

where, $\mathrm{k}_{2}$ represents pseudo $2^{\text {nd }}$ order rate constant and other symbols carry exactly the same meaning as mentioned before.
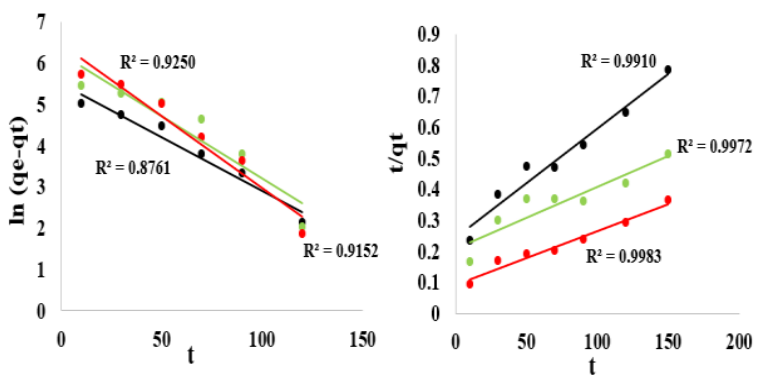

Fig. 8. Linear fittings of pseudo- $1^{\text {st }}$ (left) and pseudo- $2^{\text {nd }}$ (right) order kinetics of NCC (black), DANC (green) and DCNCs(red)

To verify the applicability of these models, experimental data for removing BB41 from wastewater using NCC, DANC and DCNC have been plotted in Fig. 8 and the results are shown in Table2. The regression coefficients $\left(\mathrm{R}^{2}\right)$ suggest that pseudo $2^{\text {nd }}$ order model complies with our experimental data more accurately than pseudo $1^{\text {st }}$ order model for all adsorbents. For DCNC, the calculated value of adsorption capacity for pseudo $1^{\text {st }}$ order model is $298.18 \mathrm{mg} / \mathrm{g}$, which is far less than our experimental value $(411.78 \mathrm{mg} / \mathrm{g})$. But, experimentally calculated adsorption capacity for pseudo $2^{\text {nd }}$ order model (434.78 $\mathrm{mg} / \mathrm{g}$ ) shows more closeness to the value derived from the experiment. Also, similar behavior has been found for NCC and DANC in terms of exploring adsorption capacity. The conformity of our experimental parameters with pseudo $2^{\text {nd }}$ order model suggests that the interaction between dye and the adsorbents is dominated by chemisorption process which can be defined by exchange or sharing of electrons[22]. For DCNC, the chemisorption process can be explained as the result of the attraction force between negatively charged surface of functionalized nano-cellulose and positively charged cationic dye.

Fig. 9, presents the reuse potential of DCNC via sequential sorption cycles. DCNC exhibits promising cycling behavior. The equilibrium adsorption capacity of the chemically regenerated DCNC is still maintained at $89.30 \%$ after fifth consecutive cycles. However, reduction in the adsorption efficiency of DCNC was also observed. The probable explanation is that the progressive saturation with time of the adsorption/active sites of the adsorbents which was not reversed in the regeneration process lessen the adsorption efficiency slightly. These findings demonstrate excellent reversibility and reusability of DCNC adsorption of cationic dyes with good adsorption performance at least fifth times.

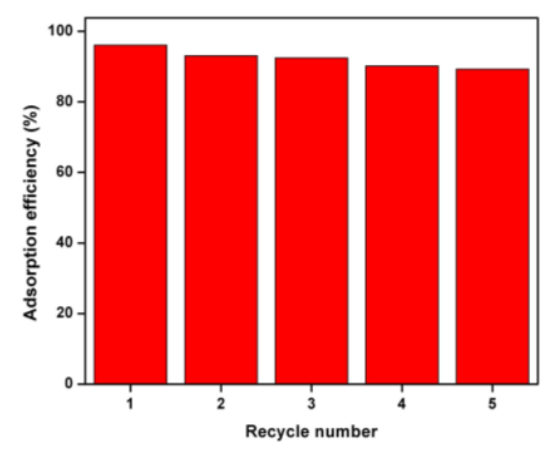

Fig. 9. Progressive adsorption efficiency cycles of DCNCs for BB41

\section{CONCLUSION}

In this work, we proposed a facile route to introduce multiple carboxyl (-COOH) groups in cellulose structure and utilized it for wastewater treatment. The synthesized adsorbent DCNC along with the intermediate product DANC were characterized using SEM and FT-IR. Experimental studies proved the efficient candidacy of DCNC for removal of cationic dyes from simulated dye polluted water. Systematic investigation of the dye removal process by each adsorbent was executed. The $\mathrm{pH}$ dependance followed similar trend for each adsorbent and $\mathrm{pH} 8$ optimum. BB41 removal rate of DCNC was encouraging, and removal percentage of more than $95 \%$ was reached at equilibrium. Kinetic studies stipulated the adsorption process was dominated by chemisorption and followed pseudo-second-order kinetic model. Maximum dye uptake was calculated from the Langmuir isotherm model and found to be $416 \mathrm{mg} / \mathrm{g}$ for DCNC; which has superiority than DANC (294 mg/g) and NCC (194 mg/g). These findings suggest that the selective oxidizing chain opening reaction introduced multiple carboxylic groups in the NCC matrix, producing an excellent biodegradable adsorbent, DCNC, which can be an efficient tool for the advanced wastewater treatment.

\section{REFERENCES}

1. Rahman, E., et al., The seed of Burmese grape (BACCAUREA RAMIFLORA) as low cost bioadsorbent for removal of methylene blue from wastewater, in ICCESD 2020: Bangladesh.

2. Eljamal, R., O. Eljamal, and N. Matsunaga, Enhancement of the Reduction and Adsorption Mechanism of nZVI using an effective polyacrylamide as a nonionic polymer, in 4th International Exchange and Innovation Conference on Engineering \& Science. 2018: Fukuoka, japan.

3. Jamshaid, A., et al., Cellulose-based Materials for the Removal of Heavy Metals from Wastewater - An Overview. ChemBioEng Reviews, 2017. 4(4): p. 240-256.

4. Hokkanen, S., A. Bhatnagar, and M. Sillanpää, A review on modification methods to cellulosebased adsorbents to improve adsorption capacity. Water Research, 2016. 91: p. 156-173. 
5. Jackson, J., et al., The use of nanocrystalline cellulose for the binding and controlled release of drugs. International journal of nanomedicine, 2011. 6: p. 321-30.

6. Abitbol, T., E. Kloser, and D.G. Gray, Estimation of the surface sulfur content of cellulose nanocrystals prepared by sulfuric acid hydrolysis. Cellulose, 2013. 20(2): p. 785-794.

7. Motiur Rahman, M., et al., Development of functionalized nanocrystalline cellulose-based polyelectrolytes with high water uptake. Polymer Journal, 2021.

8. Hossain, M.A., et al., Improvement of the strength of poly(acrylic acid) hydrogels by the incorporation of functionally modified nanocrystalline Cellulose. Materials Advances, 2020. 1(6): p. 2107-2116.

9. Falyouna, O., O. Eljamal, and I. Maamoun, Removal of Cesium from Contaminated Waters by Employing Iron-Based Nanoparticles and Nanocomposites, in Conference: International Exchange and Innovation Conference on Engineering \& Sciences (IEICES). 2019: Kyushu University - Japan.

10. Hamid, S.B.A., et al., Synergic effect of tungstophosphoric acid and sonication for rapid synthesis of crystalline nanocellulose. Carbohydrate Polymers, 2016. 138: p. 349-355.

11. Tan, X.Y., S.B. Abd Hamid, and C.W. Lai, Preparation of high crystallinity cellulose nanocrystals (CNCs) by ionic liquid solvolysis. Biomass and Bioenergy, 2015. 81: p. 584-591.

12. Yahya, M., H. Lee, and S.B. Abd Hamid, Preparation of Nanocellulose via Transition Metal Salt-Catalyzed Hydrolysis Pathway. BioResources, 2015. 10.

13. Yang, H., M.N. Alam, and T.G.M. van de Ven, Highly charged nanocrystalline cellulose and dicarboxylated cellulose from periodate and chlorite oxidized cellulose fibers. Cellulose, 2013. 20(4): p. 1865-1875.

14. Zhu, Q., et al., Activable carboxylic acid functionalized crystalline nanocellulose/PVAco-PE composite nanofibrous membrane with enhanced adsorption for heavy metal ions. Separation and Purification Technology, 2017. 186: p. 70-77.

15. Zuo, Y., et al., Preparation and characterization of dialdehyde starch by onestep acid hydrolysis and oxidation. International Journal of Biological Macromolecules, 2017. 103: p. 1257-1264.

16. Dien, L.Q., et al., Nanocellulose fabrication from Oryza sativa L. rice straw using combined treatment by hydrogen peroxide and dilute sulfuric acid solution. Energy Sources, Part A: Recovery, Utilization, and Environmental Effects, 2019: p. 1-10.

17. Ji, H., et al., Strategy towards one-step preparation of carboxylic cellulose nanocrystals and nanofibrils with high yield, carboxylation and highly stable dispersibility using innocuous citric acid. Green Chemistry, 2019. 21(8): p. 1956-1964.
18. Lafi, R., I. Montasser, and A. Hafiane, Adsorption of congo red dye from aqueous solutions by prepared activated carbon with oxygen-containing functional groups and its regeneration. Adsorption Science \& Technology, 2018. 37(1-2): p. 160-181.

19. Kaur, S., S. Rani, and R.K. Mahajan, Adsorption Kinetics for the Removal of Hazardous Dye Congo Red by Biowaste Materials as Adsorbents. Journal of Chemistry, 2013. 2013: p. 628582.

20. Adeyi, A.A., et al., Simultaneous Adsorption of Cationic Dyes from Binary Solutions by Thiourea-Modified Poly(acrylonitrile-coacrylic acid): Detailed Isotherm and Kinetic Studies. Materials, 2019. 12(18).

21. Islam, M.A., Adsorption isotherms and kinetics of ethanol onto powder and consolidated activated carbon. 2016.

22. Bhattacharyya, K.G. and A. Sharma, Kinetics and thermodynamics of Methylene Blue adsorption on Neem (Azadirachta indica) leaf powder. Dyes and Pigments, 2005. 65(1): p. 5159. 